\title{
Blood Glucose Concentration, Pancreatic Histology and Insulin-Expression following Metformin and Glibenclamide Administration in Diabetic Rats
}

\author{
Innocent A. Edagha, ${ }^{1}$ David O. Edem, ${ }^{2}$ Henry D. Akpan, ${ }^{2}$ Itoro F. Usoh, ${ }^{2}$ Edelungudi I. Edagha ${ }^{3}$ \\ 'Department of Anatomy, Faculty of Basic Medical Sciences, University of Uyo, Nigeria \\ ${ }^{2}$ Department of Biochemistry, Faculty of Basic Medical Sciences, University of Uyo, Nigeria \\ ${ }^{3}$ Department of Family Medicine, Faculty of Clinical Sciences, University of Teaching Hospital Uyo, Nigeria
}

Disclose and conflicts of interest: none to be declared by all authors

\begin{abstract}
Introduction: Introduction: Metformin and glibenclamide are used in the management of type 2 diabetes. There is paucity of information on the efficacy of insulin expression by these antidiabetic drugs. Aim: This study investigated the hypoglycemic, pancreatic histomorphological and insulin alterations following administration of metformin and glibenclamide in a type 2 diabetic model.

Materials and Methods: Thirty Wistar rats were divided into 6 groups of 5 animals each. Two groups served as normal and diabetic controls respectively. Diabetes was induced with streptozotocin (STZ). Two diabetic groups received 1.43 and 2.86 mg metformin per $\mathrm{kg}$ (body weight, bw), while another 2 groups received 0.07 and $0.14 \mathrm{mg}$ glibenclamide per kg bw respectively. Treatments lasted for 4 weeks, after which animals were fasted over-night before determination of final blood glucose levels. Pancreas was dissected for histological study.

Results: Hypoglycemic effect of glibenclamide was higher than that of metformin. The histological features of glibenclamidetreated rats demonstrated severe distortions, while metformin-treated rats had mild distortions of the pancreatic islets. Insulin expression was strongly enhanced by metformin than by glibenclamide.

Conclusion: The findings of this research may suggest the use of metformin as better alternative to glibenclamide in the amelioration of hyperglycemia, especially in the long term.

Keywords: Diabetes, Glibenclamide, Metformin, Blood glucose, Insulin, Pancreas
\end{abstract}

\section{Introduction}

Diabetes mellitus is a serious chronic disease that occurs when the pancreas does not produce enough insulin, or when the body cannot effectively use the insulin it produces. Diabetes is an important public health condition and one of the 4 priority noncommunicable diseases (NCDs) targeted for action by world leaders. The global estimates of diabetes have risen from 108 million in 1980 to 422 million as of 2014, ${ }^{1}$ a prevalence rising more rapidly in low and middle-income countries, attributable to the adoption of western lifestyle especially in the diet.

A first-line medication for the treatment of type 2 diabetes, particularly in people who are overweight is metformin, marketed as Glucophage ${ }^{\circledR} .{ }^{2}$ Metformin decreases blood glucose levels by decreasing hepatic glucose production (gluconeogenesis), decreasing the intestinal absorption of glucose, and increasing insulin sensitivity by increasing peripheral uptake and utilization of glucose. ${ }^{3}$ The drug has cardiovascular protective effects independent of glucose-lowering activity, ${ }^{4}$ and is sometimes co-administered with glibenclamide.
Glibenclamide (also known as Glyburide) is an antidiabetic drug in a class of medications known as sulfonylureas, closely related to sulfonamide antibiotics. It is the most popular sulfonylurea used in the treatment of type 2 diabetes in the United States ${ }^{5}$ It is not as good as either metformin or insulin in those who have gestational diabetes. ${ }^{6}$ The drug has been reported to be a major cause of drug-induced hypoglycemia, ${ }^{7}$ and may cause acute hemolysis, if given to persons having glucose-6-phosphate dehydrogenase deficiency. ${ }^{8}$ Glibenclamide works by binding the ATPsensitive potassium channels in pancreatic $\beta$-cells, which results in an increase in intracellular calcium in the $\beta$-cells of the pancreas and subsequent stimulation of insulin release. ${ }^{9}$

Diabetes can be induced in rodents by streptozotocin acting by inhibition of $\beta$-cell O-linked $\mathrm{N}$-acetylglucosamyl hydrolase $^{10}$ and donation of nitric oxide (NO), involved in many physiological and pathological processes in the body. ${ }^{11}$ Beta cells are clusters of cells in the pancreatic islets of Langerhans that secrete insulin, the antihyperglycemic hormone. This study investigated the effects of metformin and 
glibenclamide on blood glucose levels, pancreatic histology and insulin immunohistochemical expression in an experimental diabetic model.

\section{Materials and Methods}

\section{Experimental animals}

Thirty (30) adult male Wistar albino rats were obtained from the Faculty of Basic Medical Sciences Animal House and acclimatized for 2 weeks before use, under optimum environmental conditions of temperature $25 \pm 5^{\circ} \mathrm{C}$ with 12 hours light and dark cycle. The animals were allotted into well-maintained plastic cages. The animals were fed with pelletized growers mash (Grand Cereal Vital ${ }^{\circledR}$ Feed Ltd., Jos, Nigeria) and given tap water ad libitum. The ethics of animal care were adopted following the "Guide for the Care and Use of Laboratory Animals". ${ }^{12}$

\section{Drug Acquisition}

Streptozotocin (300 $\mathrm{mg})$ was obtained from Santa Cruz Biotechnology, Inc., U.S.A. Metformin (Glucophage) was obtained from Merck S. L. Poligono Merck Ltd., Barcelona, Spain. Glibenclamide was obtained from Nigeria German Chemical Plc, Otta, Ogun State, Nigeria. Citrate buffer was obtained from Nanjing Shuguang Silane Chemical Co., Ltd., 5611EH Eindhoven, Netherlands. Normal saline and distilled water were obtained from the laboratory of the Department of Biochemistry, University of Uyo, Nigeria.

\section{Induction of Type 2 Diabetes Mellitus}

Diabetes was induced in overnight fasted rats by a single intraperitoneal (i.p.) injection of freshly prepared streptozotocin (STZ) at $50 \mathrm{mg} / \mathrm{kg}$ body weight (bw) dissolved in $0.1 \mathrm{M}$ citrate buffer $(\mathrm{pH} 4.5)$, as earlier described. ${ }^{13}$ Control animals were injected intraperitoneally with citrate buffer alone at a single dose of $1.2 \mathrm{ml} / \mathrm{kg}$ bw. Diabetes was confirmed 3 days after STZ administration. Thereafter, fasting blood glucose levels of the animals were measured using a Glucometer (ACCU-CHECK Advantage II, Roche Diagnostics, GmbH, Germany). Following the criteria of previous workers, rats with blood glucose levels of more than $198 \mathrm{mg} / \mathrm{dL}$ were considered to be diabetic and therefore used for the study. ${ }^{14,15}$

\section{Experimental Design}

The duration of the experiment was 28 days. The 30 rats were allotted into 6 groups of 5 rats each. Group 1 served as the normal control (NC), which received 0.5 $\mathrm{ml}$ normal saline. Groups 2 to 6 received intraperitoneal injection of STZ (50 mg per kg bw) per animal. Group 2 served as the diabetic control (DC), which did not receive any drug treatment. Groups 3 and $4\left(\mathrm{D}_{\mathrm{LM}}\right.$ and $\mathrm{D}_{\mathrm{HM}}$ ) received 1.43 and $2.86 \mathrm{mg} / \mathrm{kg}$ metformin, while groups 5 and $6\left(\mathrm{D}_{\mathrm{LG}}\right.$ and $\left.\mathrm{D}_{\mathrm{HG}}\right)$ received 0.07 and 0.14 $\mathrm{mg} / \mathrm{kg}$ glibenclamide respectively. Additionally, $0.5 \mathrm{ml}$ normal saline was administered to animals in all test groups.

\section{Determination of Blood Glucose}

Blood glucose concentration was estimated by glucose oxidase method ${ }^{16}$ using a reagent kit from Randox Laboratory Ltd, UK.

\section{Histological Studies}

Excised pancreas tissues were fixed in $10 \%$ neutral buffered formalin (NBF). After 24 hours, the tissues were processed following standard protocol, ${ }^{17}$ and embedded in paraffin wax. Transverse sections of $5 \mu \mathrm{m}$ thickness were cut with the rotary microtome (Microtome Thermo Scientific - Microm HM 325, England), and used for hematoxylin and eosin staining. Insulin antibody expression was evaluated with the scoring system reported by Klien et al. ${ }^{18}$ Photomicrographs of all slides were obtained under a light microscope (Olympus - CX31, Japan), Images were obtained with Amscope digital camera (MU 1000, China) attached to the microscope, and were blindly assessed by 3 independent histopathologists.

\section{Statistical Analysis}

Statistical analyses were performed using the Primer of Statistics software version 3.01. Data in this study were expressed as means \pm standard error of mean (SEM) and analyzed using one-way analysis of variance (ANOVA) to determine the difference between the test groups compared to control, and the posthoc test (Student - Newman Keuls) for comparison between groups. Values were regarded as statistically significant at $\mathrm{p}<0.05$.

\section{Results}

\section{Effect of Metformin and Glibenclamide on Body Weights}

There was a marked percentage gain in body weight of animals $(\mathrm{g})$ in NC $(+19.47)$ when compared with DC $(+$ $0.55), \mathrm{D}_{\mathrm{LM}}(+8.15) \mathrm{D}_{\mathrm{HM}}(+13.73), \mathrm{D}_{\mathrm{LG}}(-2.7)$ and $\mathrm{D}_{\mathrm{HG}}(+13.7)$, as shown in Table 1.

\section{Effect of Metformin and Glibenclamideon Blood Glucose Levels}

The STZ-induced diabetes was evident from blood glucose readings of the day, obtained 72 hours postinduction after overnight fasting of the rats (Figure 1), showing a significant increase in blood glucose in the test groups compared to NC. However, consequent administration of metformin and glibenclamide to STZ-treated groups showed trends of blood glucose attenuation, though rats were still considered diabetic. Overall, glibenclamide elicited more hypoglycemic effect than metformin in this study. 
Table 1. Effect of Metformin and Glibenclamide Administration on Total Body Weights (g)

\begin{tabular}{|c|c|c|c|c|c|c|}
\hline \multirow{2}{*}{ Body Weight (g) } & \multicolumn{6}{|c|}{ Experimental Group } \\
\hline & NC & DC & DLM & DHM & DLG & DHG \\
\hline Initial & $127.00 \pm 5.81$ & $178.20 \pm 5.84$ & $160.40 \pm 3.89$ & $142.00 \pm 0.63$ & $157.00 \pm 0.84$ & $145.60 \pm 5.88$ \\
\hline Final & $160.20 \pm 3.99$ & $179.00 \pm 4.68$ & $174.20 \pm 5.54$ & $164.60 \pm 4.49$ & $152.80 \pm 11.21$ & $168.80 \pm 16.70$ \\
\hline Weight change (\%) & +19.47 & +0.55 & +8.15 & +13.73 & -2.7 & +13.7 \\
\hline
\end{tabular}

Data are expressed as Means \pm SEM ( $n=5$ rats per group).

Legend: $\mathrm{NC}=$ Normal Control

DC = Diabetic Control

DLM = Diabetic rats treated with low dose metformin1.43 $\mathrm{mg} / \mathrm{kg}$ body weight (bw)

$\mathrm{DHM}=$ Diabetic rats treated with high dose metformin $2.86 \mathrm{mg} / \mathrm{kg}$ bw

DLG = Diabetic rats treated with low dose glibenclamide $0.07 \mathrm{mg} / \mathrm{kg}$ bw

DHG = Diabetic rats treated with high dose glibenclamide $0.14 \mathrm{mg} / \mathrm{kg}$ bw

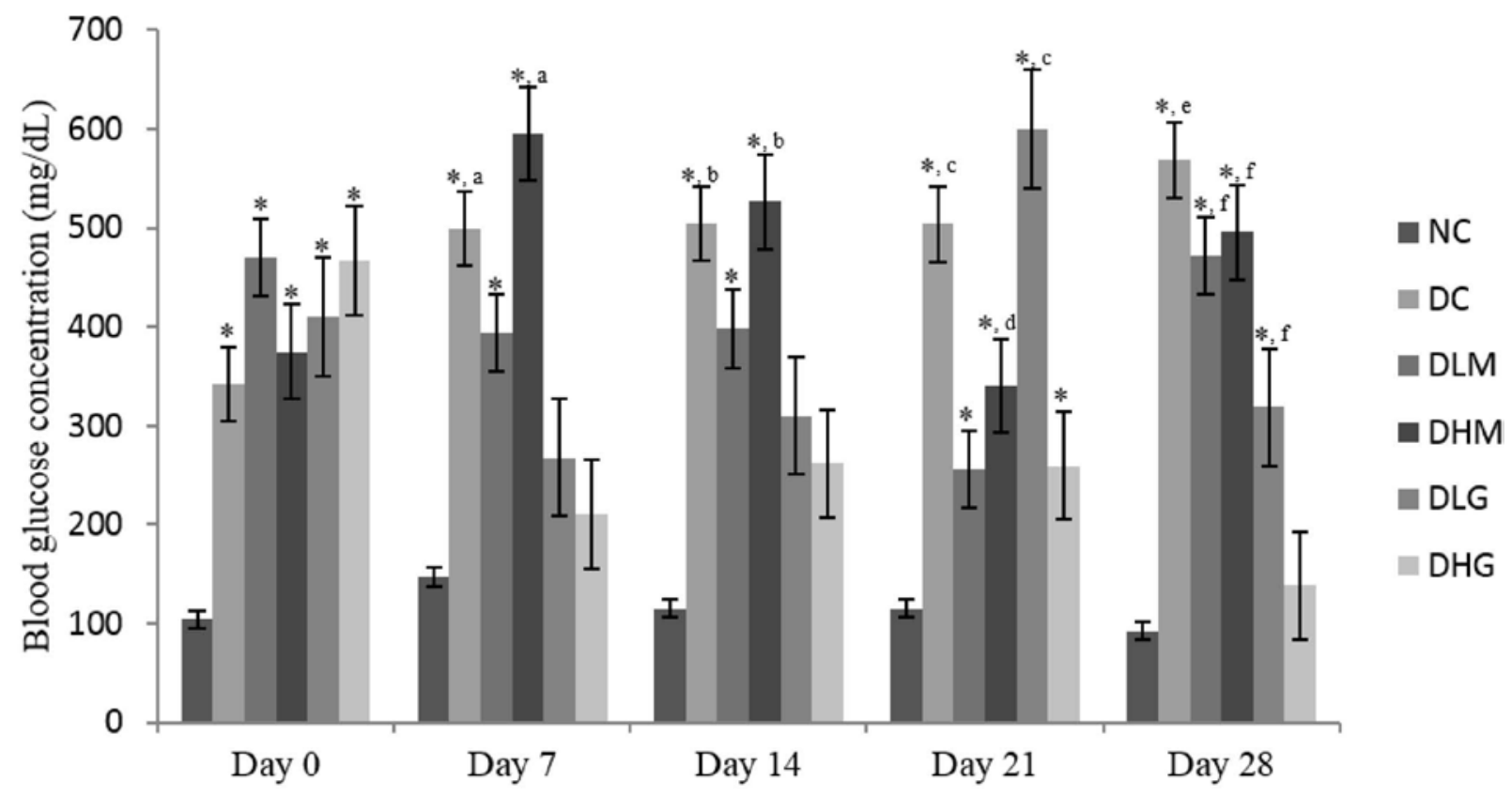

Figure 1: Effects of Metformin and Glibenclamide Administration on Blood Glucose Levels

Data are expressed as Means \pm SEM ( $n=5$ rats per group).

${ }^{*}=$ Significantly increased compared to NC $(p<0.05)$

$\mathrm{a}=$ Significantly increased compared DLG and DHG $(\mathrm{p}<0.05)$

$b=$ Significantly increased compared to DHG $(p<0.05)$

$c=$ Significantly increased compared to DLM, DHM, and DHG $(p<0.05)$

$\mathrm{d}=$ Significantly increased compared to DLM $(p<0.05)$

e $=$ Significantly increased compared to DLG and DHG $(p<0.05)$

$\mathrm{f}=$ Significantly increased compared to NC and DHG $(p<0.05)$

Legend: $\mathrm{NC}=$ Normal Control

$$
\mathrm{DC}=\text { Diabetic Control }
$$

$\mathrm{DLM}=$ Diabetic rats treated with low dose metformin $1.43 \mathrm{mg} / \mathrm{kg}$ body weight (bw)

DHM = Diabetic rats treated with high dose metformin $2.86 \mathrm{mg} / \mathrm{kg}$ bw

$\mathrm{DLG}=$ Diabetic rats treated with low dose glibenclamide $0.07 \mathrm{mg} / \mathrm{kg}$ bw

$\mathrm{DHG}=$ Diabetic rats treated with high dose glibenclamide $0.14 \mathrm{mg} / \mathrm{kg}$ bw

Effect of Metformin and Glibenclamide on Pancreatic Histology and Insulin expression

Histologically, NC group demonstrated well stained pancreatic islets $(\mathrm{Pi})$ with good nuclei morphology and cytoplasm (Fig $2[\mathrm{NC}])$. The DC rats had hypertrophied Pi nuclei, atrophied Pi cytoplasm and few necrotic nuclei of Pi with vacuolations (Fig 2 [DC]). The DM groups presented few hypertrophied, atrophied and polymorphic nuclei of $\mathrm{Pi}$, with prominent vacuolations. The DM groups exhibited numerous Pi nuclei and decreased Pi cytoplasmic volume (Fig $2\left[\mathrm{D}_{\mathrm{LM}} \& \mathrm{D}_{\mathrm{HM}}\right]$ ). The rats in the group $D_{\mathrm{LG}}$ indicated fatty necrosis especially on serous acini with vacuolations, while $\mathrm{D}_{\mathrm{HG}}$ rats had hypertrophied Pi nuclei (Fig $2\left[D_{\mathrm{LG}} \& D_{\mathrm{HG}}\right]$ ).

Immunohistochemically, the insulin antibody expression revealed (as shown in Fig 3) that there was high insulin expression in the NC, $\mathrm{D}_{\mathrm{LM}}$ and $\mathrm{D}_{\mathrm{LG}}$ groups compared with low insulin expression in the DC, $\mathrm{D}_{\mathrm{Hм}}$ and $\mathrm{D}_{\mathrm{HG}}$ groups. The corresponding immunohistochemical scores are presented in Table 2 . 


\section{Histological Observations}

Figure 2. Photomicrographs of transverse section of the pancreas ( $\mathrm{H} \& \mathrm{E}) \times 400$ $\mathrm{NC}=$ Normal control (appears normal); DC = Diabetic control (severely affected) DLM = Diabetic rat treated with low metformin $1.43 \mathrm{mg} / \mathrm{kg}$ body wt (bw) (moderately affected) DHM = Diabetic rat treated with high dose metformin $2.86 \mathrm{mg} / \mathrm{kg}$ bw (moderately affected)

DLG = Diabetic rat treated with low dose glibenclamide $0.07 \mathrm{mg} / \mathrm{kg}$ bw (severely affected)

$\mathrm{DHG}=$ Diabetic rat treated with high dose glibenclamide $0.14 \mathrm{mg} / \mathrm{kg}$ bw (moderately affected)

Key: Red arrow head - oedema, black arrow head - hypertrophied nuclei, $\mathrm{N}=$ necrosis; Sa = Serous acini; eSa = Esinophilic Serous acini; Pi = Pancreatic islets; $\mathrm{dPi}=$ degenerating and distorted Pancreatic islets; $\mathrm{Fn}=$ Region of fat necrosis; Id = Intralobular duct; $\mathrm{Va}=$ Vacuolation.
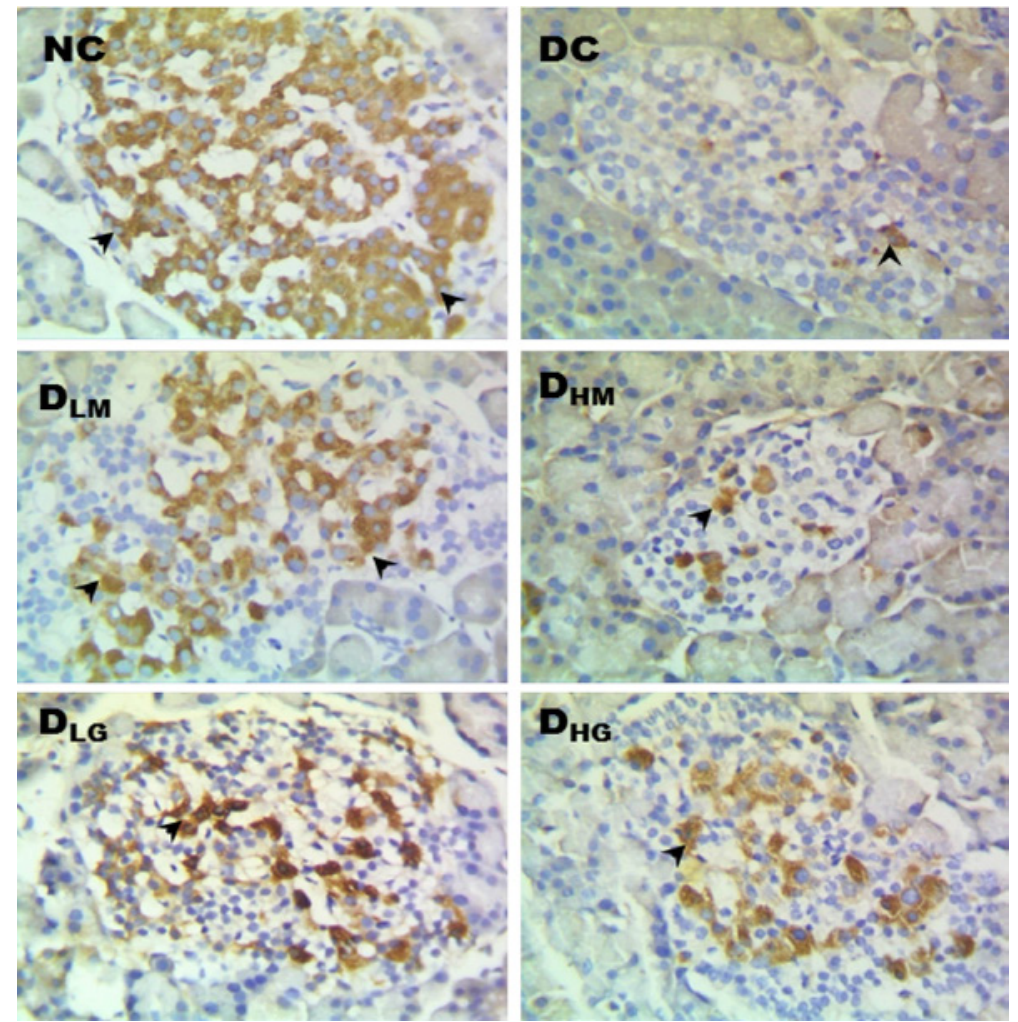

Figure 3. Photomicrographs of transverse section showing insulin antibody expression (black arrow head). Strongly expressed in NC, DLM, DLG and DHG. Weakly expressed in DC and moderately expressed in DHM (at $\times 400$ ). 
Table 2. Effect of Metformin and Glibenclamide Administration on Insulin Expression

\begin{tabular}{l|c|c|c|c}
\hline \multicolumn{1}{|c|}{ Group } & $(\mathbf{A}) \%$ of IHC & (B) Intensity of IHC & $\begin{array}{c}\text { Final score (A+B) for Insulin Antibody } \\
\text { Expression* }\end{array}$ & $\begin{array}{c}\text { Degree of Insulin Antibody } \\
\text { Expression }\end{array}$ \\
\hline $\mathrm{NC}$ & $>60(3)$ & Strong (3) & 6 & High \\
\hline $\mathrm{DC}$ & $<30(1)$ & Mild (2) & 3 & Low \\
\hline$D_{\mathrm{LM}}$ & $>60(3)$ & Strong (3) & 3 & High \\
\hline$D_{\mathrm{HM}}$ & $<30(1)$ & Mild (2) & 3 & Low \\
\hline$D_{\mathrm{LG}}$ & $<30(1)$ & Mild (2) & 6 & Low \\
\hline$D_{\mathrm{HG}}$ & $>60(3)$ & Strong (3) & High \\
\hline
\end{tabular}

Values in parenthesis indicate score for \% and intensity of IHC.

Legend: IHC = Immunohistochemistry

$\mathrm{NC}=$ Normal Control

$\mathrm{DC}=$ Diabetic Control

$D_{\mathrm{LM}}=$ Diabetic rats treated with low dose metformin $1.43 \mathrm{mg} / \mathrm{kg}$ body weight (bw)

$D_{\text {нм }}=$ Diabetic rats treated with high dose metformin $2.86 \mathrm{mg} / \mathrm{kg}$ bw

$D_{\mathrm{LG}}=$ Diabetic rats treated with low dose glibenclamide $0.07 \mathrm{mg} / \mathrm{kg}$ bw

$\mathrm{D}_{\mathrm{HG}}=$ Diabetic rats treated with high dose glibenclamide $0.14 \mathrm{mg} / \mathrm{kg}$ bw

Key: $\%$ IHC: $0=0 \%, 1=<30 \%, 2=30-60 \%, 3=<60 \%$

Intensity of IHC: $0=$ No reaction, $1=$ Weak, 2 = Mild, $3=$ Strong

* Final Score: $A+B$ (Range from 0 to 6 ): $0 / 6$ = Negative Reaction; $1 / 6$ to $3 / 6$ = Low expression;

$4 / 6$ to $6 / 6=$ High expression.

\section{Discussion}

Well-known anti-diabetic drugs metformin and glibenclamide were investigated to compare their effects on blood glucose levels, pancreatic microanatomical alterations and intensity of insulin expressed by the pancreatic $\beta$-cells, as detected with insulin antibody marker in STZ diabetic rat model.

The blood glucose levels of the STZ - induced diabetic-treated groups were statistically reduced $(\mathrm{p}<$ $0.05)$ compared to the DC group. This result indicates that metformin and glibenclamide have antidiabetic potentials as earlier documented. ${ }^{19}$ This is consistent with the report of Okonkwo and Okoye ${ }^{20}$ of a reduction in blood glucose levels in diabetic rats treated with metformin. The blood glucose lowering effect of metformin is dependent on the presence of insulin. ${ }^{21}$ This correlates with the histological result of DC group, which demonstrated that administering STZ to rats did not completely degenerate pancreatic $\beta$-cells (solely responsible for insulin production), as insulin was expressed albeit in low intensity (Fig. 3 [DC]).

Histologically, the STZ-induced diabetic group revealed features of acute pancreatitis (Fig. 2.). Morphologic alterations of acute pancreatitis span from inflammation and edema to marked necrosis and hemorrhage. These morphologic alterations may show as: (i) microvascular leakage causing edema, (ii) necrosis of fat by lipolytic enzymes and (iii) an acute inflammatory reaction. The alterations demonstrated in this study were ameliorated in the drug-treated groups, however not to the same extent.

Metformin promotes insulin binding to insulin receptors leading to a reduction in blood glucose levels, suggesting that pancreatic $\beta$-cells are not completely destroyed in diabetes mellitus (DM) type 2. Metformin has been reported to have antioxidant activity against oxidative damage caused by reactive oxygen species (ROS). ${ }^{22}$ The evidence of the attenuation of STZ-induced $\beta$-cell toxicity following metformin administration is demonstrated in the intensity of insulin antibody expressed (Fig. $3\left[\mathrm{D}_{\mathrm{LM}} \& \mathrm{D}_{\mathrm{HM}}\right]$ ).

Glibenclamide showed strong hypoglycemic potential.Insulin expression was stronglydemonstrated in $\mathrm{NC}, \mathrm{D}_{\mathrm{LM}}, \mathrm{D}_{\mathrm{HM}}$ and $\mathrm{D}_{\mathrm{HG}}$ groups. However, there were severe pancreatic islet distortions (acute pancreatitis) and high insulin expression in the glibenclamidetreated group (Fig. $3\left[\mathrm{D}_{\mathrm{HG}}\right]$ ), when compared with the metformin group (Fig. $3\left[\mathrm{D}_{\mathrm{HM}}\right]$ ).

Glibenclamide reportedly stabilizes blood glucose by binding to and inhibiting the ATP-sensitive potassium channels through the inhibitory regulatory subunit, sulfonylurea receptor 1 (SUR1) in pancreatic $\beta$-cells. The inhibition causes cell membrane depolarization, opening of voltage-dependent calcium channel which increases intracellular calcium in the $\beta$-cells, and subsequent stimulation of insulin release. ${ }^{9}$

\section{Conclusion}

The present study may suggest that the hypoglycemic effect of glibenclamide was higher than that of metformin. The histological features of glibenclamide-treated rats demonstrated severe distortions, while metformin-treated rats had mild distortions of the pancreatic microanatomy (islets of Langerhans). Insulin expression was strongly enhanced by glibenclamide than by metformin. The mechanism of action of metformin (as regards insulin utilization) is presumed to be direct and a less energydependent pathway, whereas the inverse is the case for glibenclamide. Thus the findings of this research may suggest the use of metformin as a better alternative to glibenclamide in the amelioration of hyperglycemia, especially in the long term. 


\section{References}

1.World Health Organization. Fact Sheets on diabetes. 2018; http:// www.who.int. Accessed: March 31, 2019.

2. Maruthur NM, Tseng E, Hutfless S et al. Diabetes Medications as Monotherapy or Metformin-Based Combination Therapy for Type 2 Diabetes: A Systematic Review and Meta-analysis. Annals of Internal Medicine 2016; 164: 740.

3.Kirpichnikov D, McFarlane S, Sowers J. Metformin: an update. Annals of Internal Medicine 2002;137 (1): 25 - 33.

4. Roussel R, Travert F, Pasquet B et al. Metformin use and mortality among patients with

diabetes and atherothrombosis. Archives of Internal Medicine 2010; 170(21):1892-1899.

5. Riddle MC. Editorial: Sulfonylureas differ in effects on ischemic preconditioning; is it time to retire glyburide? Journal of Clinical Endocrinology and Metabolism 2003; 88 (2): 528-530.

6. Balsells M, García-Patterson A, Solà I, Roqué M, Gich I, Corcoy R. Glibenclamide, metformin, and insulin for the treatment of gestational diabetes: a systematic review and meta-analysis. British Medical Journal 2015; 350:102.

7. Holdcraft W, Braun E. Androgen Receptor Function is required in Sertoli Cells for the Terminal Differentiation of Haploid Spermatids. Development 2004; 131(2):459-467.

8. Mutalik S, Udupa N. Glibenclamide Transdermal Patches: Physiochemical, Pharmacodynamic and Pharmacokinetic Evaluations. Journal of Pharmacological Science 2004; 93:1577- 1594. 9. Serrano-Martín X, Payares G, Mendoza-León A. Glibenclamide, a Blocker of $\mathrm{K}+($ ATP) Channels, Shows Anti-leishmanial Activity in Experimental Murine Cutaneous Leishmaniasis. Antimicrobial Agents and Chemotheraphy 2006; 50 (12): 4214-4216.

10.Vivek KS. Streptozotocin: An Experimental Tool in Diabetes and Alzheimer's disease (A Review). International Journal of Research and Development in Pharmacy 2010; 2(1):1-7. https: / / www. researchgate.net/publication/266881129_STREPTOZOTOCIN_AN_ EXPERIMENTAL_TOOL_IN_DIABETES_AND_ALZHEIMER'S_DISEASE_AReview

11. Buckley G. Martindale: The Extra Pharmacopoeia. 29 $9^{\text {th }}$ edition. Great Britain, The

Pharmaceutical Press; 1989: 1920 pp.

12. National Research Council. Guide for the Care and Use of Laboratory Animals, $8^{\text {th }}$ edition,

Washington (DC): National Academies Press (US); 2011: 1 - 217. https://grants.nih.gov/grants/.../guide-for-the-care-and-use-of- laboratory-animals.pdf

13. Lenzen S. The Mechanisms of Alloxan- and StreptozotocinInduced Diabetes. Diabetologia 2008; 51: 216-226.

14. Mustafa A, Didem D, Orhan N. In vivo antidiabetic and antioxidant potential of Helichrysum

Plicatum ssp.Plicatum capitulums in Streptozotocin-Induced diabetic rats. Journal of

Ethnopharmacology 2007; 109:54 - 59.

15. Erejuwa OO, Sulaiman SA, Wahab MS, Sirajudeen KN, Salleh MS, Gurtu S. Hepatoprotective Effect of Tualang Honey Supplementation in Streptozotocin-induced Diabetic Rats. International Journal of Applied Research in Natural Products 2012; 4(4): 37-41. https: / / www. researchgate.net/publication/278846796

16. Barham D, Trinder P. An improved color reagent for the determination of blood glucose by the oxidase system. Analyst 1972; 97 (151):142 - 145. https://www.ncbi.nlm.nih.gov/pubmed/5037807 17. Bancroft JD, Cook HC. Manual of Histological Techniques, Edinburgh, Churchill Livingstone; 1984: 201 - 202.

18. Klein M, Picard E, Vignaud JM et al. Vascular endothelial growth factor gene and protein: strong expression in and thyroid carcinoma. Journal of Endocrinology 1999; 161: 41 - 49.

19. Akyuz F, Tekin N, Aydın O, Temel HE, Isıklı B. The Effect of Metformin and Exercise on Serum Lipids, Nitric Oxide Synthase and Liver Nitric Oxide Levels in Streptozotocin-Nicotinamide Induced Diabetic Rats. African Journal of Pharmacy and Pharmacology 2012; 6(5): 336-342.

20. Okonkwo PO, Okoye ZSC. Comparative Effects of Antidiabetic Drug, Metformin and Serum Lipids, Serum Ferritin and Endocrine Indicators of Diabetes Mellitus Complications in Streptozotocin Diabetic Rats. International Journal of Biochemistry Research \& Review 2014; 4(6): 536 - 549. http://www.journalrepository.org/ media/journals/IJBCRR_3/2014/Jul/Okonkw0462014IJBCRR11811_1. pdf

21. Pournaghi P, Sadrkhanlou R, Hasanzadeh S, Foroughi A. An Investigation on Body Weights, Blood Glucose Levels and PituitaryGonadal Axis Hormones in Diabetic and Metformin-Treated Diabetic Female Rats. Veterinary Research Forum 2012; 3(2): 79-84. https:// www.vrfuuir.com

22. Cahova M, Palenickova E, Dankova $\mathrm{H}$ et al. Metformin prevents ischemia reperfusion-induced oxidative stress in the fatty liver by attenuation of reactive oxygen species formation. Am J. Physiol Gastroent. Liver Physiol 2015; 309(2): 100 - 111.
Received: july 9, 2019

Accepted: October 10, 2019
Corresponding author

Innocent A. Edagha

innocentedagha@uniuyo.edu.ng 